\title{
micromachines
}

ISSN 2072-666X

www.mdpi.com/journal/micromachines

Article

\section{Enhanced Liquid Metal Micro Droplet Generation by Pneumatic Actuation Based on the StarJet Method}

\author{
Nils Lass ${ }^{1, *}$, Lutz Riegger ${ }^{1,2}$, Roland Zengerle ${ }^{1}$ and Peter Koltay ${ }^{1,2}$ \\ 1 Laboratory for MEMS Applications, IMTEK, Department of Microsystems Engineering, University \\ of Freiburg, Georges-Koehler-Allee 103, 79110 Freiburg, Germany; \\ E-Mails: lutz.riegger@biofluidix.com (L.R.); roland.zengerle@imtek.de (R.Z.); \\ peter.koltay@biofluidix.com (P.K.) \\ 2 BioFluidix GmbH, Georges Köhler Allee 103, 79110 Freiburg, Germany \\ * Author to whom correspondence should be addressed; E-Mail: nils.lass@imtek.de; \\ Tel.: +49-761-203-73258; Fax: +49-761-203-73299.
}

Received: 5 December 2012; in revised form: 4 February 2013 / Accepted: 4 February 2013 / Published: 11 March 2013

\begin{abstract}
We present a novel pneumatic actuation system for generation of liquid metal droplets according to the so-called StarJet method. In contrast to our previous work, the performance of the device has been significantly improved: the maximum droplet generation frequency in continuous mode has been increased to $f_{\max }=11 \mathrm{kHz}$ (formerly $f_{\max }=4 \mathrm{kHz}$ ). In addition, the droplet diameter has been reduced to $60 \mu \mathrm{m}$. Therefore, a new fabrication process for the silicon nozzle chips has been developed enabling the production of smaller nozzle chips with higher surface quality. The size of the metal reservoir has been increased to hold up to $22 \mathrm{~mL}$ liquid metal and the performance and durability of the actuator has been improved by using stainless steel and a second pneumatic connection to control the sheath flow. Experimental results are presented regarding the characterization of the droplet generation, as well as printed metal structures.
\end{abstract}

Keywords: StarJet; metal droplets; 3D-printing; rapid prototyping; droplet generator; microparticle; soldering; bumping 


\section{Introduction}

The generation of liquid metal micro droplets is a challenging area in the field of microelectromechanical systems (MEMS) technologies. It is applicable in a large field of applications, such as the generation of electrical 2D/3D connections or metal layers in the field of microelectronics or MEMS [1,2], e.g., creation of solder bumps for flip chip bonding, rapid prototyping of electric circuits [3] or 3D prototyping of small metal structures [4,5], e.g., printing of porous masters for thermoforming. However, the generation of single microdroplets from molten metal at high temperatures is a highly complex task for several reasons: first of all, the device must operate at temperatures above the melting point of the metal. Therefore, all parts of the device have to be either made of temperature stable materials or have to be thermally insulated from the hot parts of the system. Especially piezoelectric actuators have to be insulated [1] or actively cooled to prevent their destruction [6], because their operation temperature is limited by the Curie temperature, typically ranging between $150{ }^{\circ} \mathrm{C}$ and $300{ }^{\circ} \mathrm{C}$ [7,8]. Also, the mechanical stress induced by heating up or cooling down the dispensing device is a major challenge that requires certain design rules to be considered (e.g., use of material combinations with suitable modulus of elasticity and appropriate thermal expansion coefficients). Furthermore, the molten metal inside the device, as well as the ejected droplets, have to be protected from oxidation by, e.g., the application of an inert gas [9], as the formation of oxides on the molten liquid solder could inhibit the generation of droplets [10].

The devices developed so far for generation of metal droplets can be divided into two categories: the first ones are Drop-on-Demand-devices (DoD), where each droplet is generated by a single actuation. Therefore, the timing of the droplet generation and deposition of single droplets can be controlled very precisely [11]. Thus, accurate printing of microstructures or patterns can be realized easily by a sequence of actuation pulses. Still, these devices normally operate only at low frequencies. That is why such droplet generators are used in parallel or with multiple nozzles for printing larger structures or patterns $[11,12]$. The other category of metal dispensers is the group of continuous-mode devices, which generate metal droplets by a capillary break-up of molten metal jets. To this end, disturbances are induced into a liquid metal jet, using for example piezoelectric stack actuators $[6,13]$. Due to the continuous jetting, these devices eject droplets at much higher frequencies than the DoD-devices. However, the control of individual droplet deposition is more complex and requires solutions to deflect unwanted droplets into waste or gutter following continuous inkjet-devices. Orme et al. $[6,13,14]$, for example, used a set of capacitors for charging and deflecting single droplets emerging from a continuous jet. Consequently, both kinds of droplet generators have specific advantages and disadvantages, depending of the field of application.

The droplet generator considered in this paper provides both kinds of operation modes, Drop-on-Demand, as well as continuous-mode within the same setup, facilitating its usage in a wide field of applications. The StarJet system (see Figure 1a) consists of the printhead and a pneumatic setup. The former features a heater cartridge inside the reservoir and a tubular heater surrounding the reservoir to ensure a constant melt temperature. Therefore, the temperature is measured by a thermocouple placed near to the reservoir outlet enabling a closed control loop. The pneumatic system entails two pressure controllers for adjusting the actuation/rinse pressure of the system and a pneumatic valve for controlling drop-on-demand mode. 
Figure 1. (a) Schematic drawing of the StarJet system. (b) Model drawing of a metal droplet inside entering the star-shaped nozzle chip (grey); the reservoir outlet is represented by the blue structure.

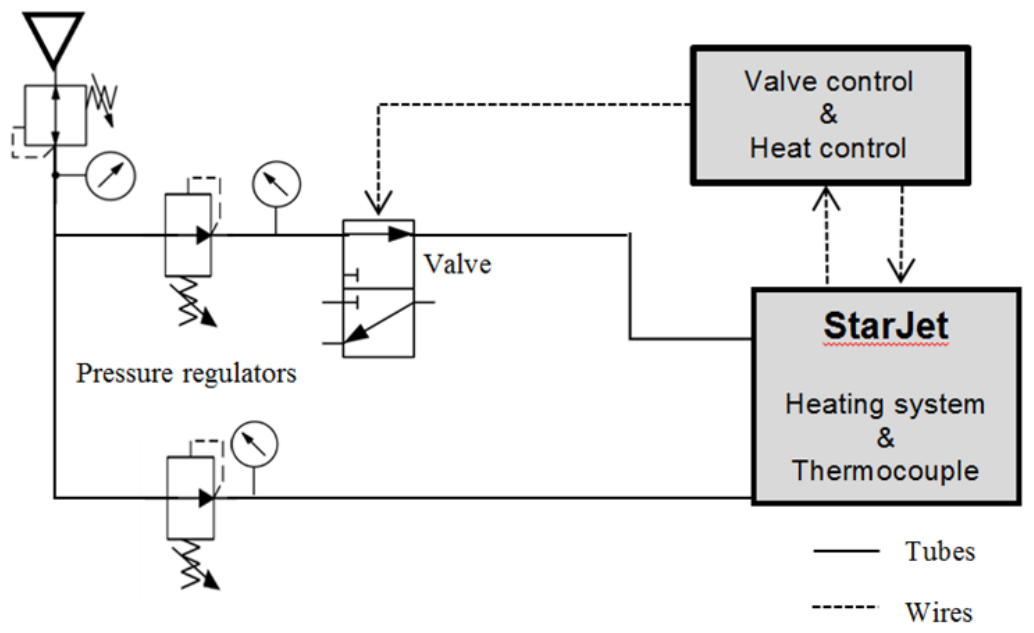

(a)

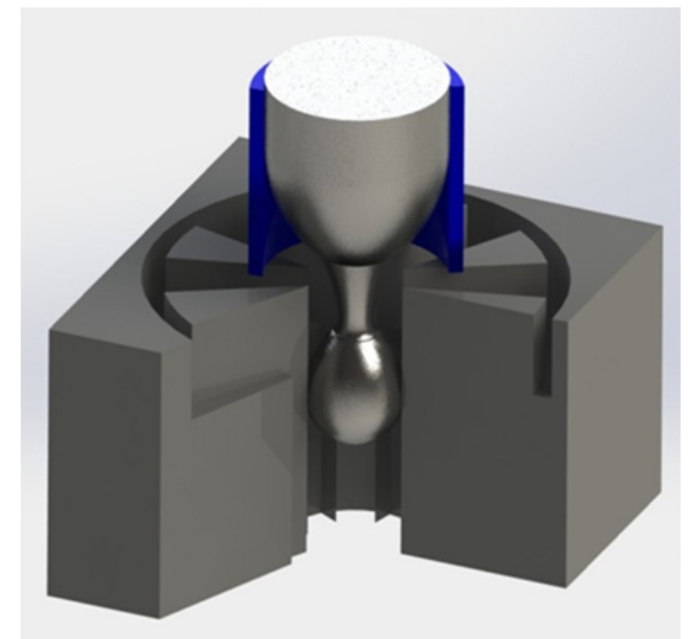

(b)

The centerpiece of the printhead is the MEMS-fabricated nozzle chip (Figure 1b). This chip is connected to a reservoir containing the molten metal. By applying a pressure to the rinse inlet of the system, a gas flow can be set up through the star shaped channels on top of the chip. This flow provides two functions. First, it inhibits the oxidation of the molten metal inside the chip, and in addition, it enforces a droplet breakup when a metal flow is established, due to the applied pressure. Then, after droplet tear-off, the star-shaped structure centers the generated metal droplets inside the nozzle by capillary force and allows the gas flow to cover the droplet (see Figure 1b). In that way, the droplet is still shielded from oxidation and gets accelerated until it is ejected. For the droplet generation in DoD mode, short pressure pulses are applied onto the reservoir by opening the pneumatic valve for short periods of time. Each of these pulses enforces a little amount of molten metal inside the nozzle chip, where the just mentioned star-shaped structure in combination with the rinse pressure leads to the generation of single droplets. Hence, the printing frequency can be controlled by adjusting the valve timing. For operating the device in continuous mode, a constant pressure is applied on top of the reservoir by permanently opening the valve. Droplets are then generated continuously at a certain natural frequency. This frequency is mainly based on the actuation parameters, which define how much metal flows inside the chip per time. However, the frequency is also influenced by the design of the nozzle chip and fluid properties, like the viscosity and surface tension. A detailed description of the method can be found in [15]. All connections are sealed by high temperature stable materials. Thus, the limitation for the maximum operating temperature is the melting point of the actuator material itself, only. Furthermore, the gas flow, which works as actuation mechanism, avoids the oxidation of the liquid metal inside the reservoir of the device, as well as the dispensed metal droplets in flight. In consequence, devices according to the StarJet method should be suitable for generating liquid metal droplets of many kinds of metals, even with high melt temperatures without suffering from the aforementioned common problems. 


\section{Fabrication and Experimental Setup}

\subsection{Fabrication of the Actuator}

The body of the previously published actuator modules of the StarJet droplet generators V0 and V1 were made of brass providing good properties in terms of thermal conductivity and ease of mechanical machining $[15,16]$. During the experimental characterization of these devices, however, we observed the brass being corroded after contact with molten solder. Therefore, the diameter of the reservoir outlet tube, i.e., the channel, which connects the reservoir to the nozzle chip, was enlarged during operation by this corrosive effect. The primarily smooth surface of the reservoir outlet tube (ROT) was transformed into a rough, non-uniformly shaped channel (see Figure 2); thereby, the diameter was enlarged by $56 \%$ from $500 \mu \mathrm{m}$ to $780 \mu \mathrm{m}$. As the diameter of this channel essentially determines the fluid dynamics of the system, this degradation has a strong influence on the operating frequency of the printhead.

Figure 2. Top view: reservoir outlet tube (ROT) of the StarJet V1 device before (a) $R=250 \mu \mathrm{m}$ and after (b) $R=390 \mu \mathrm{m}$ operation at $T=230{ }^{\circ} \mathrm{C}$ using solder $(\mathrm{Sn} 95 \mathrm{Ag} 4 \mathrm{Cu})$.

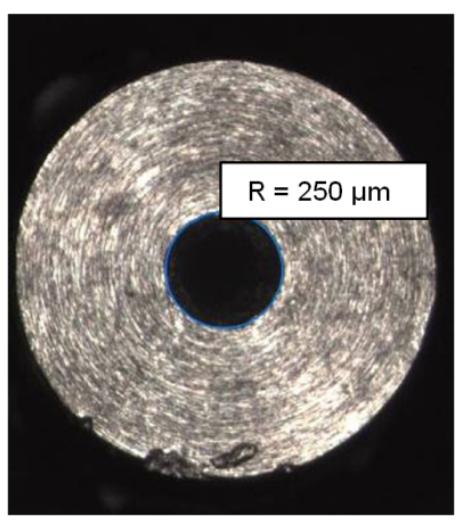

(a)

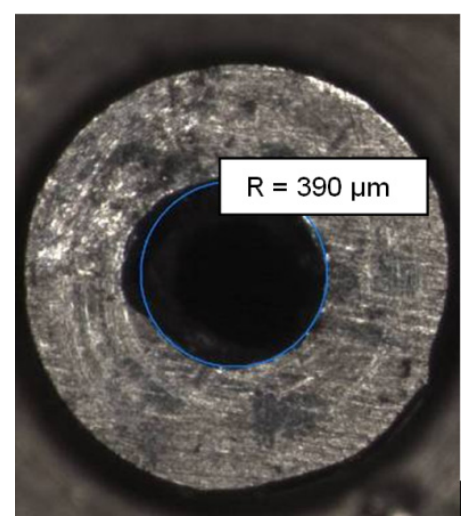

(b)

In addition, the previously used polytetrafluoroethylene (PTFE) fittings degraded during operation at temperatures higher $T=200{ }^{\circ} \mathrm{C}$. So, the minimum pressure values required for droplet generation increased during experiments, due to leakage of the actuating nitrogen gas flow. Thus, the experimental results produced with devices V0 and V1 exhibited poor reproducibility. Another critical point identified during experiments was the small reservoir volume of the devices. The generated droplets typically had a diameter of approximately $270 \mu \mathrm{m}$, which equals a volume of $V_{\text {droplet }}=0.0825 \mathrm{~mm}^{3}$. Operating with a frequency of $f=120 \mathrm{~Hz}$ and a reservoir volume of $V_{\text {reservoir }}=127 \mathrm{~mm}^{3}(\mathrm{~V} 0)$, the droplet generator could only be used for a maximum time of about $12 \mathrm{~s}$ in continuous-mode. Then, the device had to be cooled down and disassembled in order to be refilled. The characterization of these devices was, therefore, time-consuming and cumbersome. To overcome these problems, we designed an improved actuator, referred to as V2, made of stainless steel (Figure 3a), enabling higher working temperatures and enhanced durability. In particular the problem regarding the corrosion of the ROT is fixed by the improved device, because stainless steel is impervious to the corrosiveness of the molten solder and will consequently not be dissolved. We measured the ROT 
diameter of the reworked actuator after 30 days of operation, and no decrease in width could be determined. Furthermore, the fittings are now made of Nova-Mica-Thermex ${ }^{\circledR}$ and are temperature stable up to $900{ }^{\circ} \mathrm{C}$. For an extended operation time, the reservoir was enlarged from previously $V_{\text {reservoir }}=127 \mathrm{~mm}^{3}$ to $22,000 \mathrm{~mm}^{3}$, enabling the printing of extensive structures.

In addition the new device V2 features an opening on top enabling refill in hot condition. Another new feature of the device is that it can be used with two separated gas supplies (Figure $3 b$ ) for rinsing and actuation pressure to enable the investigation of the influence of these actuation parameters on the performance independently. Using this setup, the single pressure pulses required for DoD-mode can now be applied more precisely ensuring reliable operation.

To facilitate the assembly of nozzle chip and actuator and to ensure precise chip centering, we designed a new holding fixture for the nozzle chip, which is depicted in the close-up view on Figure $3 b$. The chip is centered by a laser fabricated positioning spring and is pressed against the ROT by a heat stable cup spring (Inconel ${ }^{\circledR}$ alloy) with a defined pressure to ensure a leak-proof connection between the bypass-channels and the gas channels leading to the inlet. The ROT diameter has been reduced from $400 \mu \mathrm{m}$ to $200 \mu \mathrm{m}$, resulting in a higher capillary pressure, inhibiting an undesired leakage of molten metal, due to hydrostatic pressure when the nozzle chip is removed. Based on the radius and the molten metal properties, the maximum possible fill height was calculated [17].

Figure 3. Enhanced StarJet actuator made from stainless steel (a). Model cross section view of the StarJet V2 and close-up of the chip mounting section (b); blue arrows indicate the pneumatic actuation.

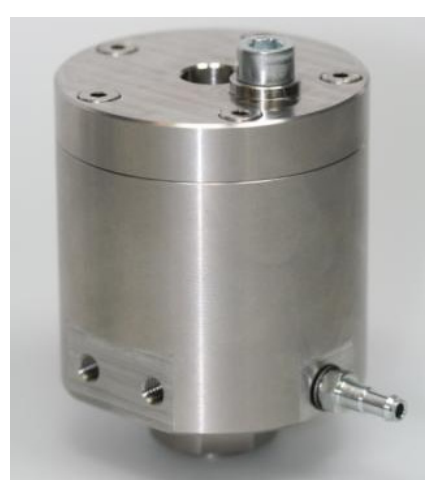

(a)

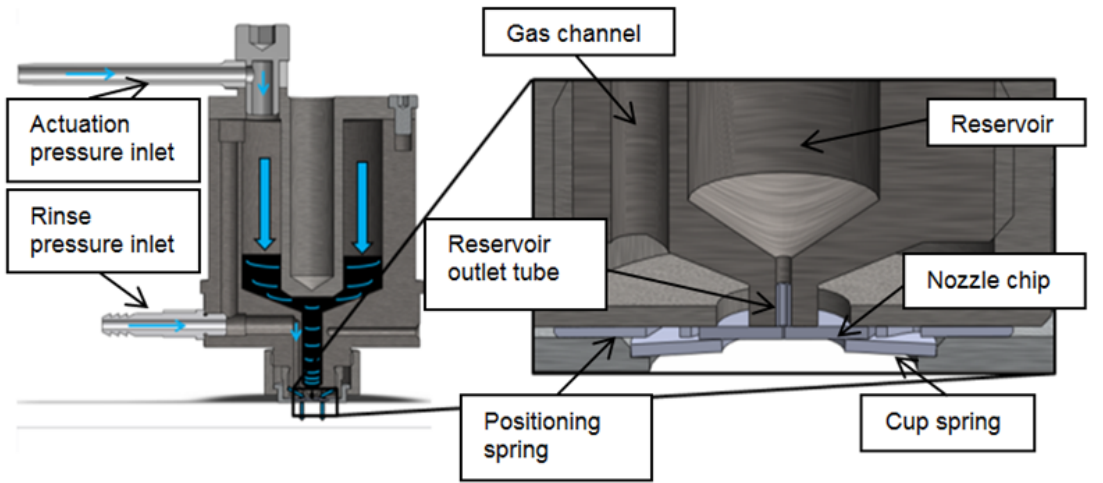

(b)

The basic assumption for calculation is a contact angle of $\Theta=120^{\circ} \pm 5^{\circ}$ for solder on stainless steel, a surface tension of $\gamma=0.493 \mathrm{~N} / \mathrm{m}$, a density of $\rho=7500 \mathrm{~kg} / \mathrm{m}^{3}$ and radius of the reservoir. With the reduced ROT diameter, the device can now be theoretically filled up without dripping to a height of

$h=6.5 \mathrm{~cm}$ (reservoir height $h=6.2 \mathrm{~cm}$ ) instead of $3.2 \mathrm{~cm}$ for the previous prototype. Because of the increased size of the device, a band heating element covering the reservoir (Tuerk-Hillinger GmbH, Bandcap heater custom, $P=800 \mathrm{~W}$ ) and a cartridge heater (Hotset GmbH, Typ HHP T $10 \times 40,120$ $\mathrm{W})$ inside the reservoir were added. With this configuration, the metal inside the reservoir can be heated up to $500{ }^{\circ} \mathrm{C}$ in less than $30 \mathrm{~min}$ and a constant temperature in the whole melt is guaranteed. The temperature is monitored by a NiCr-Ni thermopile sensor placed close to the reservoir outlet. The 
measured temperature is then used for a closed-loop temperature regulation. The temperature control, as well as the valve control, is realized by a self-developed electronic control unit, which is connected to a PC via USB port. This unit allows for precise, time-defined actuation of the actuation valve in combination with autonomous control of the reservoir temperature. For realizing short actuation pulses in DoD-mode, we installed an external high-speed solenoid valve (Festo GmbH, VPPMS), enabling opening times down to $2 \mathrm{~ms}$, resulting in a more precise droplet generation in DoD-mode. The valve is placed in front of the gas inlet for actuation. So, the gas flow of inert gas for pneumatic actuation can be switched between a low pressure $(10 \mathrm{hPa}$ to $30 \mathrm{hPa})$ to prevent oxidation of the molten metal inside the reservoir and a higher actuation pressure $(150 \mathrm{hPa}$ to $1000 \mathrm{hPa})$ initiating the droplet ejection. The rinse pressure can be adjusted separately to match to the actuation pressure.

\subsection{Experimental Setup}

The experimental setup (Figure 4) presented in this paper consists of the described StarJet actuator mounted onto a modified iBiospot ${ }^{\circledR} 600$ automation system (Biofluidix GmbH, Freiburg, Germany), providing a PC-controlled $\mathrm{x} / \mathrm{y} / \mathrm{z}$-linear stage. Hence, in contrast to earlier work, the distance between nozzle and substrate could now be adjusted during experiments. Furthermore, the iBiospot ${ }^{\circledR}$ provides an interface for triggering the valve so the valve can be actuated in respect to the position of the substrate. In addition, a spinning axis or a rotating substrate can be mounted into this machine, which enables to print tube-like structures.

Figure 4. iBiospot $^{\circledR} 600$ (reference image) from BioFluidix GmbH with mounted StarJet printhead (close-up).

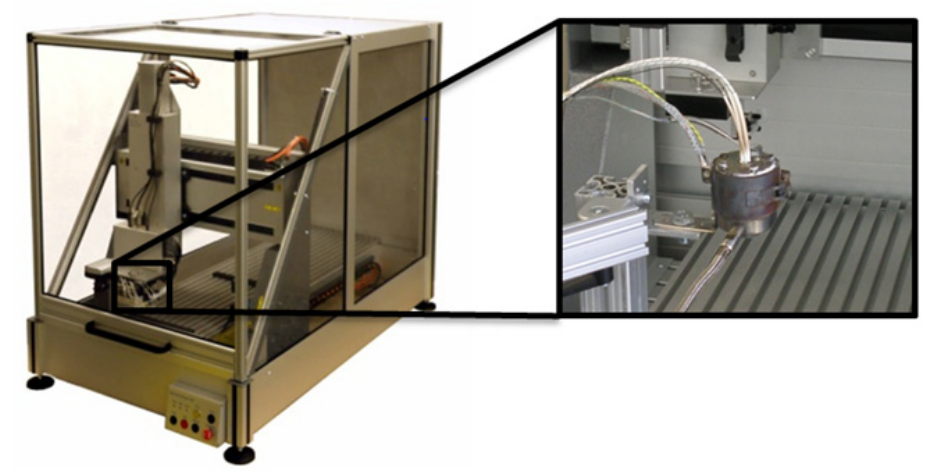

Because the design changes described before, the StarJet droplet generator is now able to dispense at significantly higher frequencies in continuous operation mode. Therefore, it is no longer feasible to measure the droplet generation frequency using the acoustic method applied in [15]. We therefore mounted a high speed camera (imagine source, MINI 2) next to the nozzle outlet for determining the dispensing frequencies visually. We record the droplet ejection with rates up to 100,000 frames per second. From this data, the frequency of the droplet ejection could be calculated and also the shape and trajectory of the flying droplets could be observed.

\subsection{Fabrication of the Nozzle Chips}


Compared to the previously presented fabrication process, P0 [15], the quality of the star shaped nozzle chips was further improved. Previously, chips with nozzle diameter smaller than $D=70 \mu \mathrm{m}$ could not be produced in the required quality. The small dimensions of the nozzles lead to a very high aspect ratio of up to 42 . Therefore, a steady through etching of the nozzle chips with the used deep reactive-ion etching (DRIE) dry etching technique [15] could not be guaranteed. The high etching time for through etching of the chips in combination with the previously used SOI mask-layer led to strong charging, and therefore, notching effects at the $\mathrm{SiO}_{2}$ interface during fabrication, like described in literature $[18,19]$. This over-etching previously results in a very poor quality of the channels at the nozzle outlet (see Figure 5a) and inside the chip (see Figure 6a).

Figure 5. Top view on nozzle outlet fabricated with old process P0 described in [15] (a), and top view on nozzle outlet fabricated with enhanced process P1 described below (b).

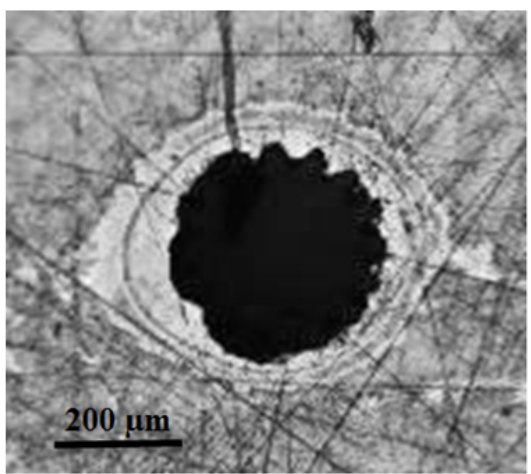

(a)

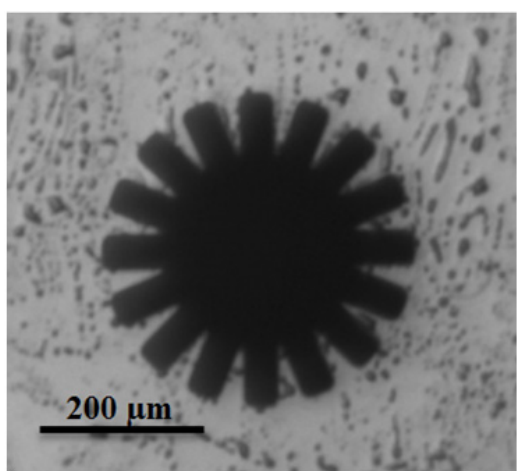

(b)

Figure 6. Cross section view (scanning electron microscope (SEM)) of the nozzle chip fabricated with old process P0 described in [15] (a), and cross section view (SEM) of the nozzle chip fabricated with enhanced process P1 described below (b).

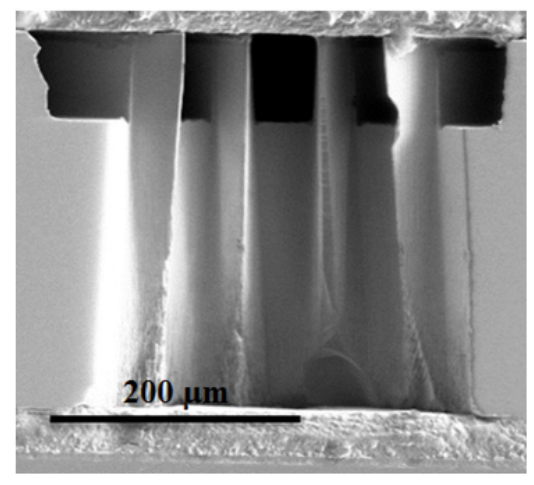

(a)

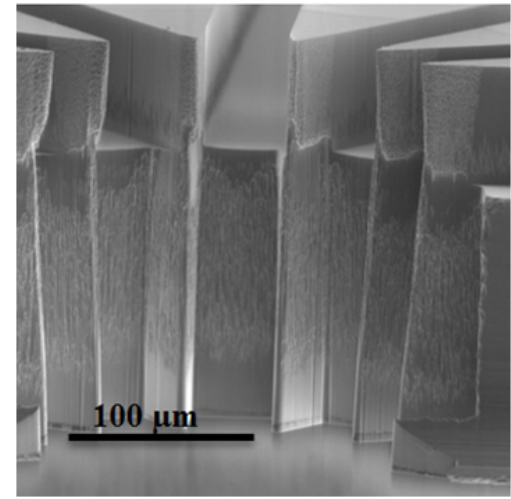

(b)

With the objective of a minimum nozzle diameter of $50 \mu \mathrm{m}$ (smallest structures equaling $10 \mu \mathrm{m}$ ) and higher quality of the shape inside the nozzle chip, we developed an enhanced MEMS fabrication process, referred to as $\mathrm{P} 1$. To minimize the aspect ratio we reduce the chip thickness from $525 \mu \mathrm{m}$ to $300 \mu \mathrm{m}$. In addition, we use a double sided fabrication process (Figure 7) instead of the originally used single side method. 
Figure 7. Schematic view of the current fabrication process (P1) for the StarJet nozzle chips (cross-section view).

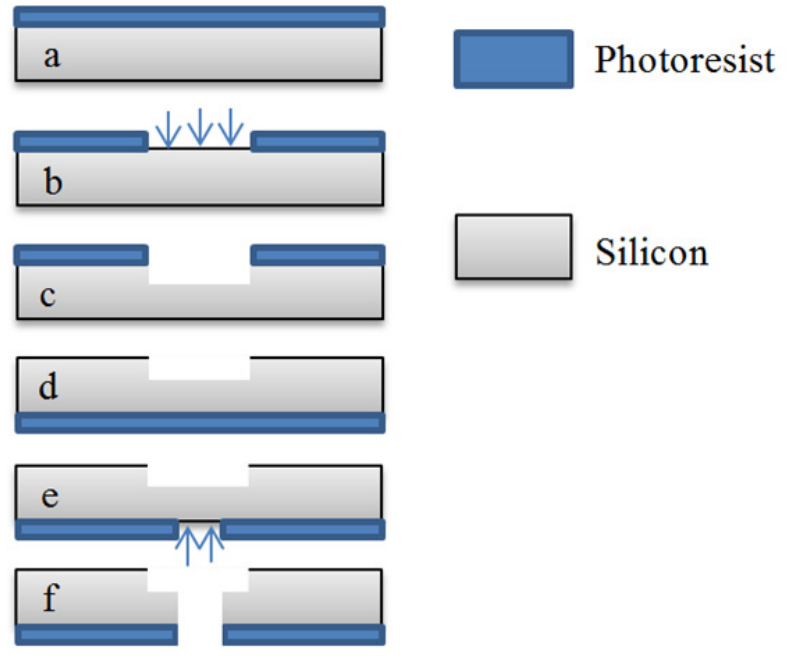

The star-shaped structures and the bypass channels are etched into a $300 \mu \mathrm{m}$ thick silicon wafer first. Therefore, a photoresist layer (Microchemicals AZ 1518, $5 \mu \mathrm{m}$ ) is spin-coated onto the wafer (Figure 7a). Then, the photoresist is structured with the geometry of the bypass channels using a chrome mask (Figure 7b). After development of the photoresist, the structure is dry etched (STS Mutiplex ICP etch) $100 \mu \mathrm{m}$ deep into the silicon (Figure 7c). After stripping and cleaning, a resist layer (Microchemicals AZ 1518, $10 \mu \mathrm{m}$ ) is again spin-coated onto the backside of wafer (Figure 7d). This layer is then photo-lithographically structured with the profile of the nozzle shape (Figure 7e). Using this mask, the wafer is finally etched through (Figure $7 \mathrm{f}$ ) before the chips are cleaned and separated by dicing. Using this double sided process, the aspect ratio could be decreased from 50 to 20 , leading to a much smoother surface inside the nozzle chips (see Figure 6b). Consequently, by using this process, the quality of the nozzle chips could be significantly improved (see Figure 5b). The dimensions of the used nozzle chips are listed in Table 1.

Table 1. Dimensions of the nozzle chips.

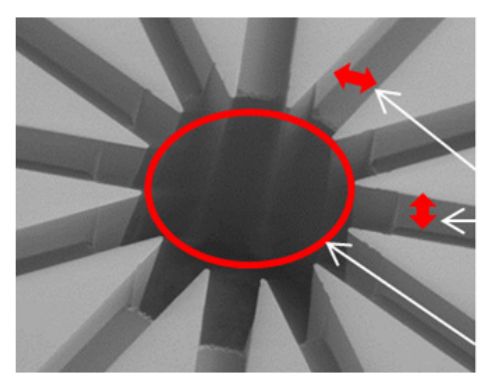

\begin{tabular}{lccccc}
\hline Nozzle Chip & $\# 2$ & $\# 6$ & $\# 12$ & $\# 5$ & $\# 21$ \\
\hline Number of bypass channels & 8 & 12 & 12 & 12 & 16 \\
Width of bypass channels $(\mu \mathrm{m})$ & 20 & 20 & 40 & 10 & 20 \\
Depth of bypass channels $(\mu \mathrm{m})$ & 100 & 100 & 100 & 100 & 100 \\
Nozzle length $(\mu \mathrm{m})$ & 300 & 300 & 300 & 300 & 300 \\
Nozzle diameter $(\mu \mathrm{m})$ & 59 & 89 & 183 & 50 & 144 \\
\hline
\end{tabular}

\section{Experimental Section}

\subsection{Characterization of StarJet Prototype V2}

Like mentioned before, results obtained with the previous setup V1 cannot be quantitatively compared to the current setup V2, because the designs of the actuator and the nozzle chips underwent major changes. Therefore, a full characterization of the novel device V2 was needed. As the StarJet 
technology features two different dispensing modes, the Drop-On-Demand-mode and the continuous-mode (for details see [15]), experiments were performed using both operation modes. In continuous-mode, droplets are issued from the nozzle continuously at a certain "natural" frequency. This frequency primarily depends on dimensions of the ROT, the nozzle geometry, the liquid properties and the applied actuation pressure in combination with the rinse pressure. Keeping all parameters as constant as possible, still each nozzle chip design features an individual frequency range depending on the specific dimensions of nozzle diameter and star shaped bypass channels. For the first experiments with the StarJet V2, we used the "single channel" setup (Figure 8) and compared the performance of different nozzle designs at different actuation pressures. In the "single channel" configuration, the internal channels for actuation and rinse pressure are connected, leading to a common inlet. Thus, the pressure values for actuation pressure and rinse pressure are kept on the same level during the experiments.

Figure 8. (a) Model cross section view of the StarJet V2 with a single gas supply for "single channel" operation; red arrows indicate the pneumatic gas flow. (b) Model cross section view of the StarJet V2 with two channel gas supply; blue arrows indicate the pneumatic gas flow.

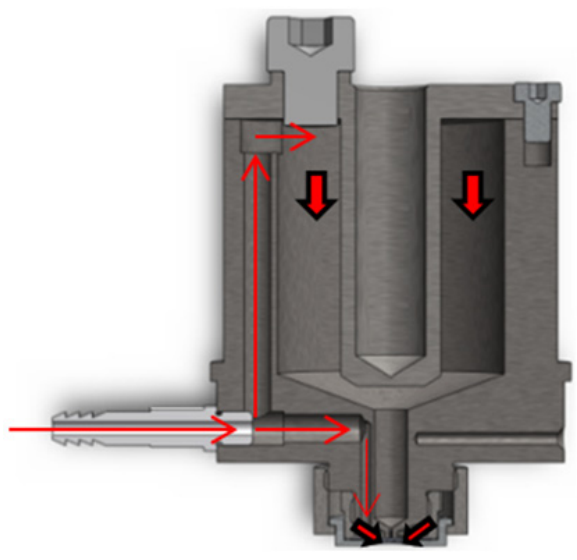

(a)

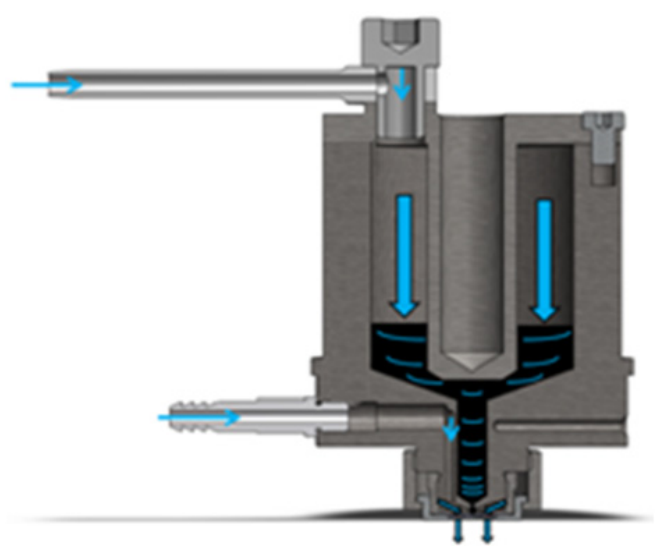

(b)

Depending on the chip geometry (nozzle diameter, bypass channels, etc.), each type of nozzle chip can be operated in a certain frequency range. In that range, the droplet ejection frequencies can be adjusted in an almost linear way by the actuation pressure. Here, the minimum pressure, which is needed, depends on the nozzle design. For nozzles with smaller diameters, higher pressures are required. Figure 9 and Figure 10 illustrate these circumstances. While Figure 9 shows the correlation between the actuation pressure and the droplet generation frequency for a nozzle chip (\#12) with a diameter of $D=183 \mu \mathrm{m}$, the nozzle chip (\#6) used for the experiments depicted in Figure 10 had only a diameter of $D=89 \mu \mathrm{m}$. The larger nozzle chip starts operation at a frequency of about $50 \mathrm{~Hz}$ at a minimum actuation pressure of 0.13 bar. By raising the pressure the frequency can be increased up to nearly $775 \mathrm{~Hz}$ before the chip stops generating droplets and starts continuous jetting at pressures higher than 0.26 bar. The smaller chip needs 0.18 bar to start operating like depicted in Figure 10. Here, the adjustable range begins with a minimum frequency of approximately $740 \mathrm{~Hz}$, and ends with almost $6500 \mathrm{~Hz}$ when a pressure of 0.32 bar is applied. When comparing the frequencies of the two 
nozzle chips for a fixed pressure value, for example at a pressure of 0.25 bar, it can be seen that the larger nozzle chip ejects droplets at approx. $f_{0.25 \mathrm{bar}}=720 \mathrm{~Hz}$ with a diameter of $D=189 \mu \mathrm{m}$, while the smaller chip operates at a nearly $370 \%$ higher frequency of $f_{0.25 \mathrm{bar}}=2650 \mathrm{~Hz}$ and a droplet diameter of $D=120 \mu \mathrm{m}$ for the same pressure. This correspondents to a flow rate with respective coefficient of variation $(\mathrm{CV})$ as calculated in Table 2.

Table 2. Calculated flow rate and coefficient of variation (CV) according to measurements depicted in Figures 9 and 10.

\begin{tabular}{cccccc}
\hline $\begin{array}{c}\text { Nozzle Chip } \\
\text { Diameter }\end{array}$ & $\begin{array}{c}\text { Mean Droplet } \\
\text { Diameter }\end{array}$ & $\begin{array}{c}\text { Minimum } \\
\text { Flow rate }\end{array}$ & $\begin{array}{c}\text { Maximum } \\
\text { Flow rate }\end{array}$ & $\begin{array}{c}\text { Minimum } \\
\text { CV }\end{array}$ & $\begin{array}{c}\text { Maximum } \\
\text { CV }\end{array}$ \\
\hline $183 \mu \mathrm{m}$ & $189 \mu \mathrm{m}$ & $175 \mathrm{~nL} / \mathrm{s}$ & $2.7 \mu \mathrm{L} / \mathrm{s}$ & $0.7 \%$ & $19.7 \%$ \\
$89 \mu \mathrm{m}$ & $120 \mu \mathrm{m}$ & $669 \mathrm{~nL} / \mathrm{s}$ & $5.8 \mu \mathrm{L} / \mathrm{s}$ & $3.0 \%$ & $12.3 \%$ \\
\hline
\end{tabular}

Figure 9. Droplet generation frequency as a function of the actuation pressure (one channel setup, nozzle chip (\#12), number of measurements per data point $N=10$.

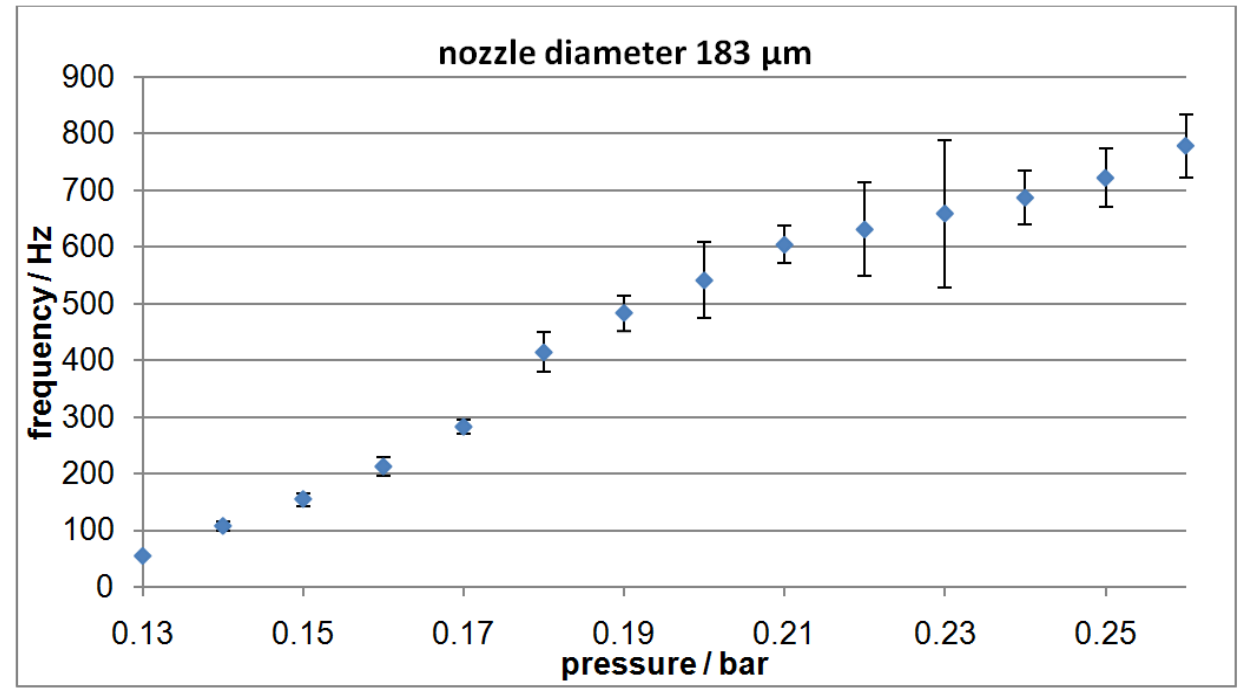

Figure 10. Droplet generation frequency as a function of the actuation pressure (one channel setup, nozzle chip (\#6); number of measurements per data point, $N=10$ ).

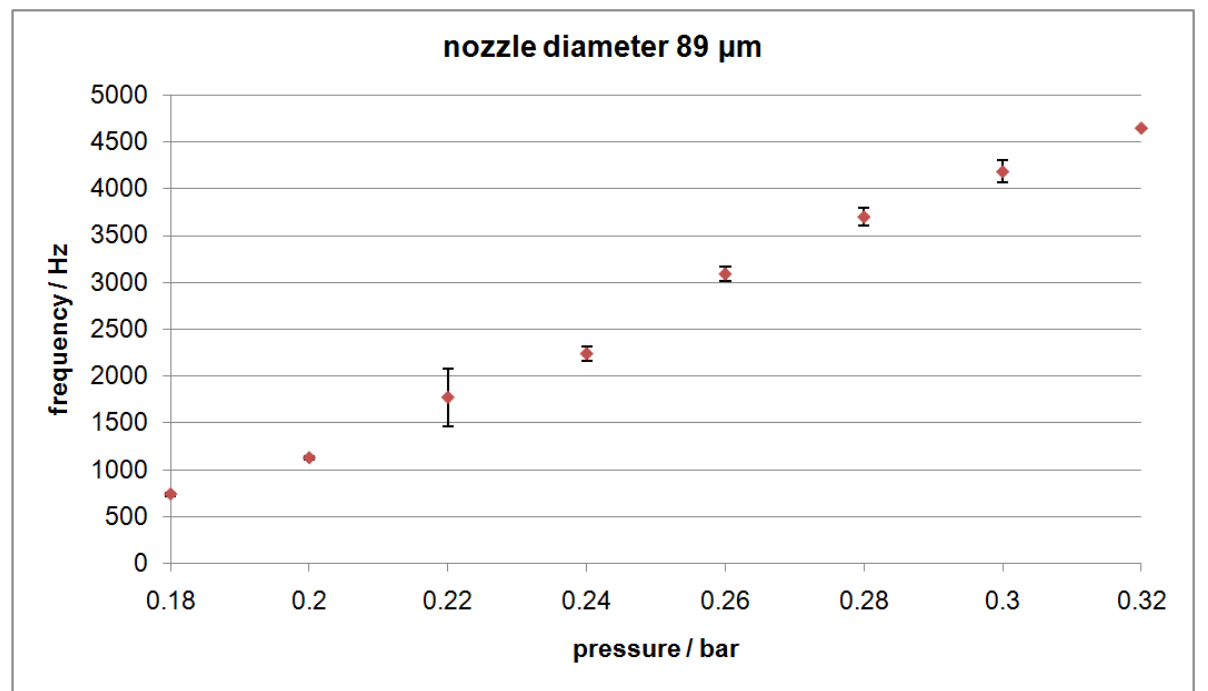


The generated droplets were ejected into a surfactant-enriched water solution with a low surface tension in order to preserve a spherical droplet shape allowing a precise measurement of their diameter after solidification using an optical microscope. We have analyzed a sample of 387 droplets produced with a $D=144 \mu \mathrm{m}$ diameter nozzle chip. In that case, the mean value amounts to $D_{\text {mean }}=148.4 \mu \mathrm{m}$ with a standard deviation of $5.6 \mu \mathrm{m}$ leading to a $\mathrm{CV}$ of $3.8 \%$.

In order to improve our understanding of the dispensing process and especially the influence of the rinse pressure, the StarJet droplet generator V2 features two separate gas inlets (cf. Figure 8b). Thus, the rinse pressure (lower inlet) can be adjusted independently of the driving pressure (upper inlet, cf. Figure 8b). This enables droplet frequency adjustment at fixed driving pressure. If the rinse pressure applied via the bypass-channels is high enough to constrict the metal column, a droplet is generated. Otherwise, if $P_{\text {rinse min }}$ is too small, the device starts producing a continuous molten metal jet.

If the actuation pressure is kept at a constant value, the frequency rises with increasing rinse pressure up to a maximum value where the rinse pressure completely blocks the generation of droplets inside the nozzle and no liquid metal is ejected anymore at this actuation pressure value. In that way, the dispensing frequency can be controlled by the adjustment of these two pressure values. This zone is indicated by the blue frames in Figure 11. Above a certain actuation pressure value, the liquid metal column is forced through the nozzle without being disturbed by the rinse pressure any more. Then, the maximum dispensing frequency for a certain nozzle chip design is exceeded. For instance Figure 11 illustrates the dependency for a chip design with a nozzle diameter of $59 \mu \mathrm{m}$.

Figure 11. Droplet generation frequency as a function of the rinse pressure (two channel setup) in combination with fixed actuation pressures. The blue marks (max. adjustable frequency for given actuation pressure) belongs to the highest rinse pressure for proper operation, and the red marks (min. adjustable frequency for given actuation pressure) belongs to the lowest rinse pressure for proper operation (nozzle diameter $D=59 \mu \mathrm{m}$ ).

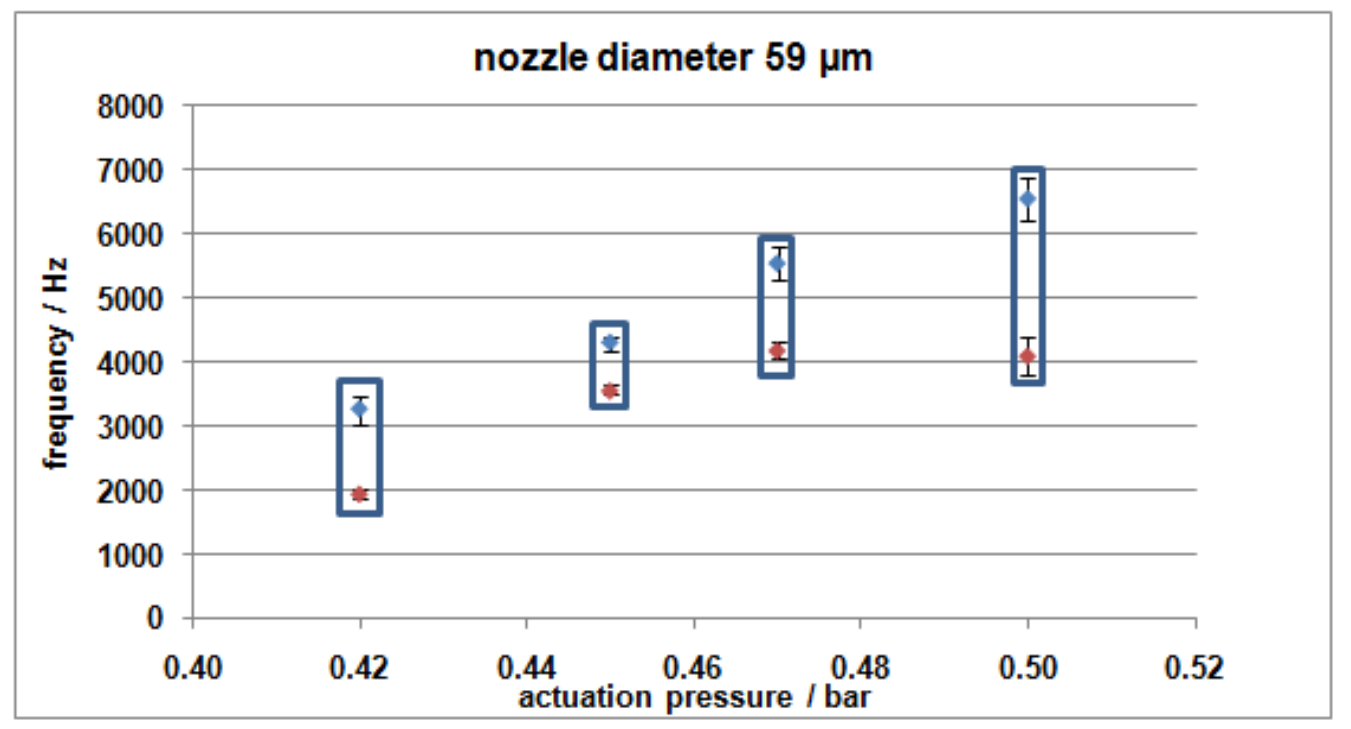

In several experiments with different chip designs, frequencies in the range from $f_{\min }=200 \mathrm{~Hz}$ to $f_{\max }=11 \mathrm{kHz}$ where evaluated. With the redesigned nozzle, a minimum droplet diameter of $D_{\min }=60 \mu \mathrm{m}$ (Figure 12a) has been achieved using $50 \mu \mathrm{m}$ nozzle chips (chip \#5). We also observed that droplet 
trajectory and the occurrence of satellites can be optimized by the rinse pressure. The droplet diameter is primarily defined by the nozzle size ( $D=50 \mu \mathrm{m}$ to $360 \mu \mathrm{m}$ tested) and slightly influenced by the dispensing frequency.

For switching the device from continuous-mode to DoD-mode no setup changes are required. Only the control of the valve has to be changed. Instead of a continuous actuation pressure, the pressure is now applied in short pulses, each leading to the ejection of one single droplet. This is conducted by opening a solenoid valve periodically for a short time (typically $t=2-5 \mathrm{~ms}$ ). The rinse pressure is applied all the time to prevent oxidation at the nozzle outlet. A suitable valve opening time in combination with an appropriate actuation pressure has been experimentally determined for each nozzle chip, leading to the ejection of one single droplet. The used parameters are listed in Table 3.

Table 3. Printing parameters for Drop-on-Demand experiments.

\begin{tabular}{lccc}
\hline & Nozzle Chip \# 2 $(\mathbf{5 9} \boldsymbol{\mu m})$ & Nozzle Chip \# 6 (89 $\boldsymbol{\mu m})$ & Nozzle Chip \# 21 (144 $\boldsymbol{\mu m})$ \\
\hline Reservoir temperature & $320{ }^{\circ} \mathrm{C}$ & $320{ }^{\circ} \mathrm{C}$ & $500{ }^{\circ} \mathrm{C}$ \\
Valve opening time & $3 \mathrm{~ms}$ & $2 \mathrm{~ms}$ & $2 \mathrm{~ms}$ \\
Actuation pressure value & $0.25 \mathrm{bar}$ & $0.2 \mathrm{bar}$ & $0.2 \mathrm{bar}$ \\
Rinse pressure value & $0.15 \mathrm{bar}$ & $0.10 \mathrm{bar}$ & $0.2 \mathrm{bar}$ \\
Droplet diameter & $88 \mu \mathrm{m}$ & $144 \mu \mathrm{m}$ & $180 \mu \mathrm{m}$ \\
\hline
\end{tabular}

The printhead was successfully tested in DoD-mode for $5 \mathrm{~h}$ without interruption at frequencies up to $25 \mathrm{~Hz}$ and a temperature of $T=320^{\circ} \mathrm{C}$. Then, the reservoir of the printhead was cleaned and filled with zinc alloy (ZAMAK, (Zn96A14) $\left.T_{\mathrm{m}}=420^{\circ} \mathrm{C}\right)$. This was heated up to $T=500{ }^{\circ} \mathrm{C}$. Using a nozzle Chip \#21 with an opening of $D=144 \mu \mathrm{m}$, single monodisperse metal droplets were generated featuring a diameter of $D=180 \mu \mathrm{m}$ (see Figure 12b).

Figure 12. (a) SEM image of metal (solder: $\mathrm{Sn} 95 \mathrm{Ag} 4 \mathrm{Cu}$ ) droplet dispensed into soar water with diameter of $D=60 \mu \mathrm{m}$. (b) SEM image of dispensed metal (ZAMAK: Zn96A14) droplets with diameter of $D=180 \mu \mathrm{m}$.

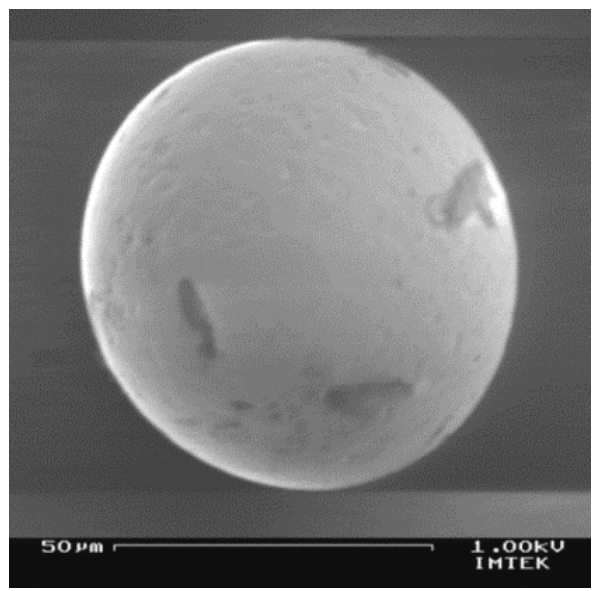

(a)

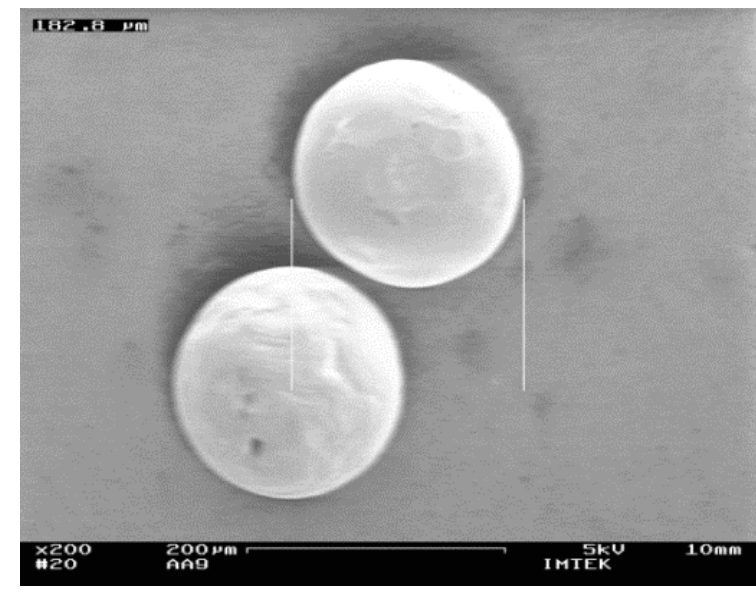

(b)

At the current development state of the StarJet, the limiting factor for the maximum operating temperature is the thermal stability of the used sealing materials (Nova-Mica-Thermex ${ }^{\circledR}$ up to $900{ }^{\circ} \mathrm{C}$ ). Therefore, the so-far reached temperature of $500{ }^{\circ} \mathrm{C}$ does not reflect the upper limit of the system, and 
we plan to reach higher temperatures in order to print higher melting materials. In continuous mode, the lowest adjustable frequency was $200 \mathrm{~Hz}$. Here, the limiting factor is the minimum achievable mass flow through the reservoir outlet tube, which is mainly defined by the actuation pressure that has to be applied to overcome the capillary pressure of the ROT. The maximum frequency is defined by the pressure value, which leads to a jetting behavior of the device. Then, the corresponding mass flow is too high and the molten metal, which enters the nozzle chip is not separated into single droplets. The size of the smallest droplets is defined by the nozzle chip. Here, the limiting factor is the fabricability of the nozzle chip geometry, because, due to decreasing diameters of the nozzle, the aspect ratio of the structures increases. This raises the difficulty of fabrication and especially the through etching of the nozzle chips. So far, we have successfully produced nozzle chips with diameters down to $50 \mu \mathrm{m}$.

\subsection{Printing in DoD-Mode}

For the printing experiments, we installed a nozzle (\#6 with a diameter of $D=59 \mu \mathrm{m}$ ) inside the printhead and heated it up to $T=320^{\circ} \mathrm{C}$. We used solder ( $\mathrm{Sn} 95 \mathrm{Ag} 4 \mathrm{Cu}$ ) for these experiments, because this material provides a short heat-up and cool-down cycle, due to its low melting point $\left(T_{\text {melt }}=210^{\circ} \mathrm{C}\right)$. For evaluating the long term stability of the process, we successfully printed a pattern consisting of more than 10,000 droplets onto a substrate using DoD-mode. Frequencies between $0.5 \mathrm{~Hz}$ and $25 \mathrm{~Hz}$ were selected. The pattern depicted in Figure 13 was printed without disruption at a frequency of $10 \mathrm{~Hz}$ with a pitch of $0.4 \mathrm{~mm}$. The diameter of the droplets on the substrate was approximately $88 \mu \mathrm{m}$.

Figure 13. (a) Picture of a Drop-on-Demand (DoD)-mode printed pattern (solder: $\mathrm{Sn} 95 \mathrm{Ag} 4 \mathrm{Cu}$, droplet diameter $D=88 \mu \mathrm{m}$ ) using a constant pitch of $400 \mu \mathrm{m}$. (b) Picture of a DoD-mode printed pattern (solder: $\mathrm{Sn} 95 \mathrm{Ag} 4 \mathrm{Cu}$, droplet diameter $D=144 \mu \mathrm{m})$ using an increasing pitch for each line $(50 \mu \mathrm{m} \rightarrow 500 \mu \mathrm{m})$.

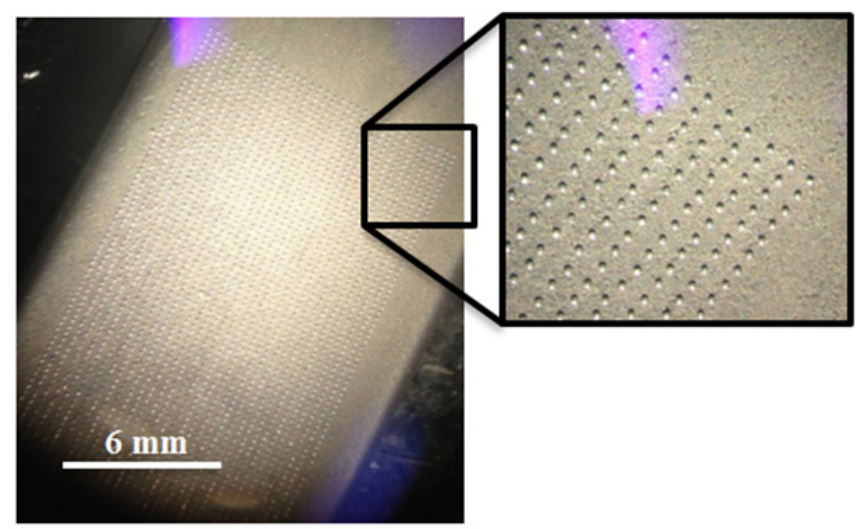

(a)

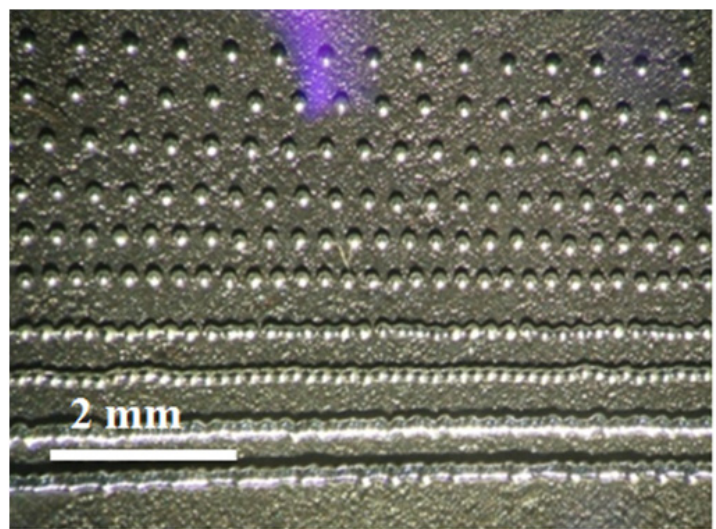

(b)

During the next experiments, we used a nozzle chip (\#6) with a diameter of $D=89 \mu \mathrm{m}$, resulting in droplets with diameters of approximately $144 \mu \mathrm{m}$. Here, the pitch was decreased continuously in steps of $50 \mu \mathrm{m}$ from $0.5 \mathrm{~mm}$ to $0.05 \mathrm{~mm}$. As can be seen in Figure 13 (b), single droplets merge when the pitch gets smaller than the single droplet diameter. In that way, solid structures can be formed without using a reflow process. 
The software for controlling the stage system provides a so-called bitmap dispense mode, which enables to convert the pixels of a $b / w$ bitmap into a grid of printed droplet with a given pitch. Using this mode, we printed the affiliation logo of our research institute on an aluminum substrate (see Figure 14). Again, we used a nozzle chip (\#2) with a diameter of $D=59 \mu \mathrm{m}$, generating droplets of $D=88 \mu \mathrm{m}$. This was done with a frequency of $5 \mathrm{~Hz}$.

Figure 14. Picture of a DoD-mode printed affiliation logo of the IMTEK; droplet diameter approx. $88 \mu \mathrm{m}$.

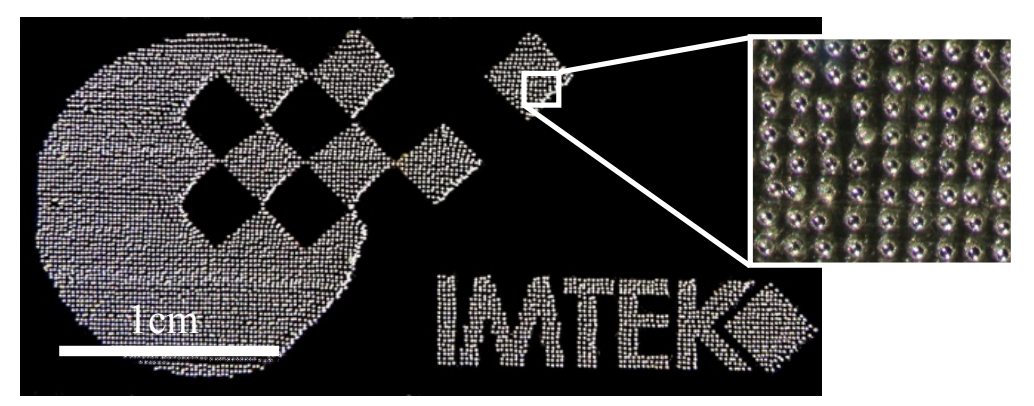

Again, using the nozzle chip (\#6) with a diameter of $D=89 \mu \mathrm{m}\left(D_{\text {droplet }}=144 \mu \mathrm{m}\right)$, a pitch of $150 \mu \mathrm{m}$ and a droplet generation frequency of $10 \mathrm{~Hz}$, we investigated the feasibility of fabricating three-dimensional structures. For instance, we printed multiple lines of solder on top of each other. The print distance was kept to $1.5 \mathrm{~mm}$ continuously by adjusting the z-axes. The printed walls had a length of $4 \mathrm{~cm}$ and heights up of $2 \mathrm{~mm}$ (see Figure 15a). The rinse pressure was set to the minimal possible value leading to the generation of a droplet. In that way, the droplets had the lowest adjustable velocity when leaving the nozzle. Consequently, the droplets kept their spherical shape when they hit the surface (see Figure 15a). So, the printed structures had a regular surface with average surface roughness of $R_{t}=6.3 \mu \mathrm{m}$ (see Figures $15 \mathrm{~b}$ and 16 ).

Figure 15. (a) Picture of in DoD-mode printed IMTEK logo, droplet diameter approximately $144 \mu \mathrm{m}$. (b) Surface measurement of the printed wall.

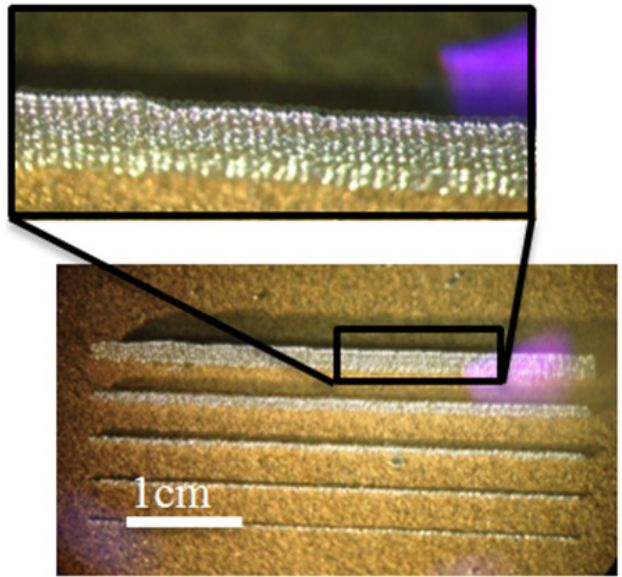

(a)

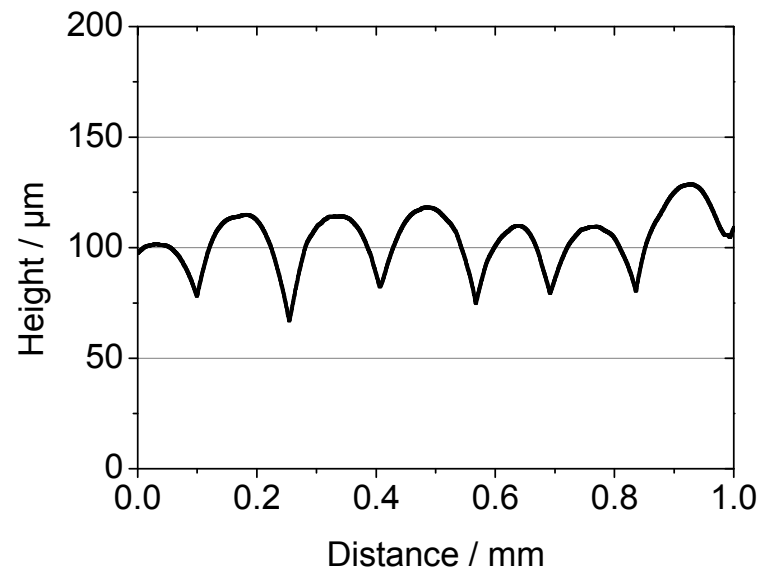

(b)

The close-up view shows that single droplets are precisely placed on top of each other without failures. Thus, strongly uniform structures can be created without, e.g., a thermal reflow process. This 
example demonstrates the small deviations of the droplet trajectory from the symmetry axis of the nozzle and the high uniformity of the droplets.

Figure 16. Close up view (SEM picture) of in DoD-mode wall; droplet diameter approximately $144 \mu \mathrm{m}$.

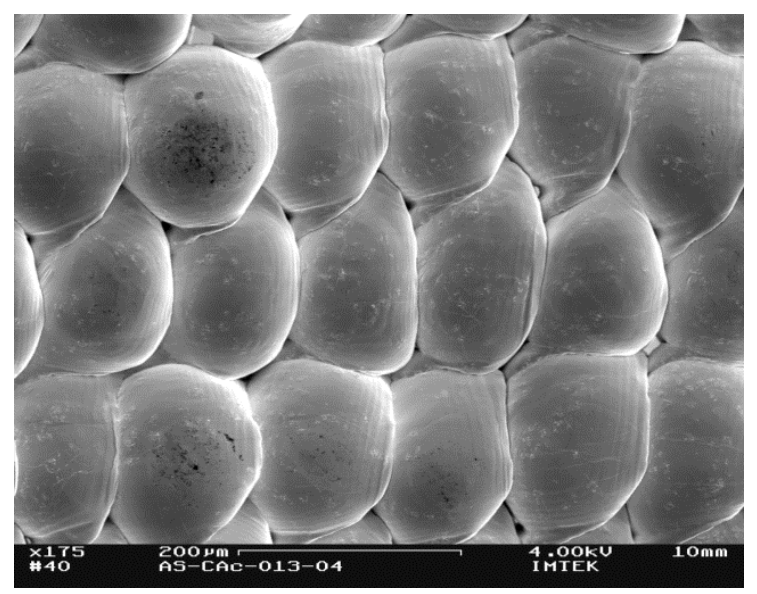

\subsection{Printing in Continuous-Mode}

For the printing experiments using the continuous-mode we printed droplets onto a rotating substrate. In that way, the pitch could be adjusted by adapting the distance between the center of the substrate and the printhead manually. We used a nozzle chip (\#6) with a diameter of $D=89 \mu \mathrm{m}$, ejecting droplets with diameters of $D=120 \mu \mathrm{m}$, and the device was heated up to $T=250{ }^{\circ} \mathrm{C}$ ( $p_{\text {actuation }}=p_{\text {rinse }}=0.3$ bar $)$. In contrast to the printing experiments in DoD-mode, the printing distance between the nozzle and the substrate was fixed at $15 \mathrm{~mm}$ and could not be adapted during printing. Using a frequency of approximately $f=4 \mathrm{kHz}$ and a pitch two times larger than the respective droplet diameter, we created tube-like structures with porous walls, like depicted in Figure 17.

Figure 17. (a) Picture of a printed tube (diameter $10 \mathrm{~mm}$ ). (b) SEM picture of the surface of a continuous-mode printed tube. (c) Surface measurement of the printed tube.

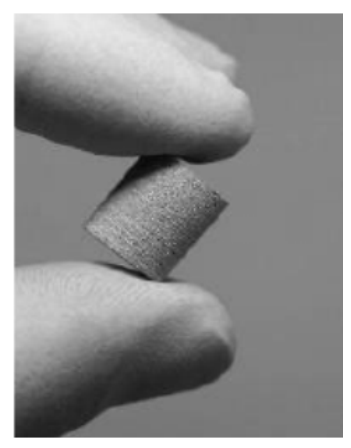

(a)

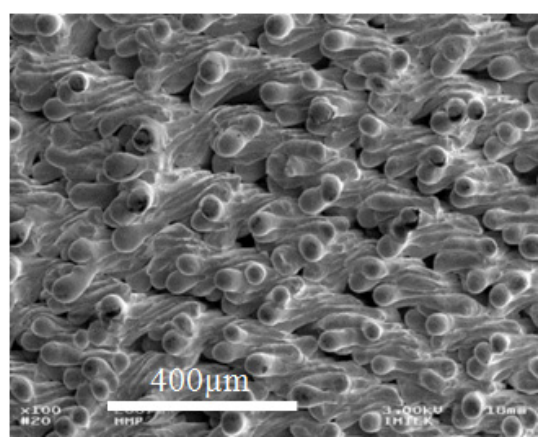

(b)

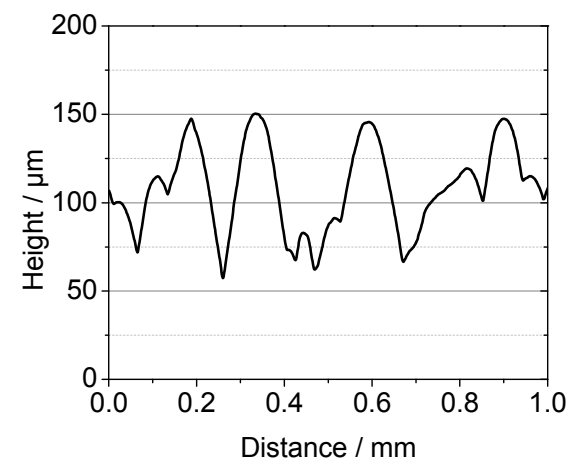

(c)

The close-up view (see Figure 17b) reveals that the droplets lose their spherical shape and solidify in a deformed state, while impinging on the solid. This leads to the high surface roughness, as well as to an enhanced wall thickness of $300 \mu \mathrm{m}$ compared to the droplet diameter of $D=120 \mu \mathrm{m}$. Based on 
the results of S.D. Aziz [20], the reason for the splashing of the droplets is probably the higher velocity of the flying droplets caused by the larger rinse pressures. The surface of the printed structure has again been measured with a profiler (Tencor, P11) to characterize the roughness of the walls. The structure exhibits an average surface roughness of $R_{t}=15.1 \mu \mathrm{m}$ (see Figure 17c).

Figure 18. Picture of two coils (Diameter $10 \mathrm{~mm} / 6 \mathrm{~mm}$ ) printed at $350{ }^{\circ} \mathrm{C}$ metal temperature with close up view (SEM-picture) of the surface.

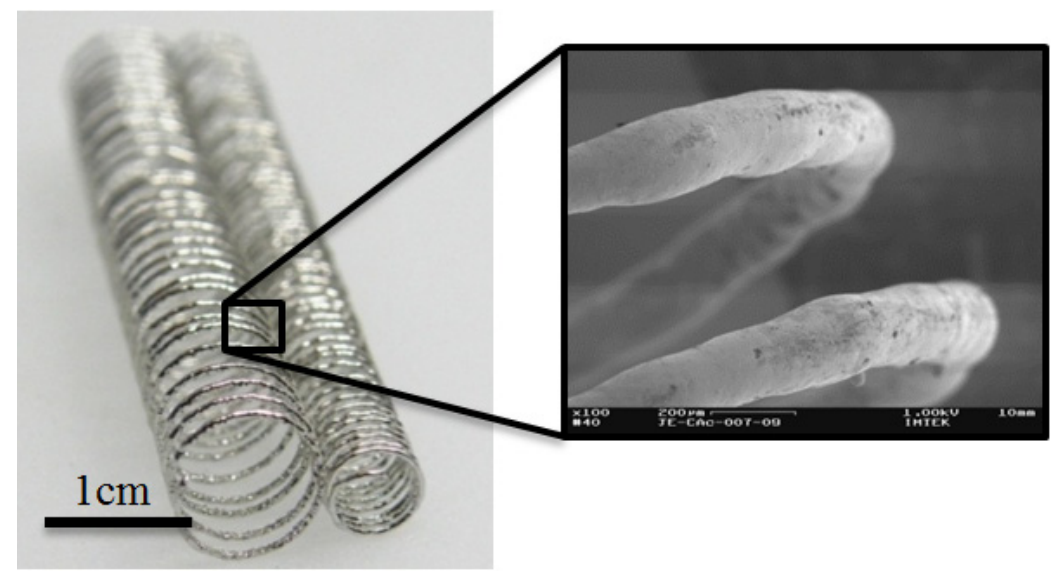

By dispensing (frequency of $5.5 \mathrm{kHz}, T=350{ }^{\circ} \mathrm{C}$ ) single droplets onto a horizontal spinning axis mounted on a linear stage while moving this spinning axis under the printhead, coils can be fabricated (see Figure 18) using continuous operation mode. The adaptation of the dispensing frequencies and the rotation velocity of the axis allowed for printing homogeneous structures (pitch approx. $50 \mu \mathrm{m}$ ). Here, the single droplets merge after impact, resulting again in a solid structure (see close-up in Figure 18). The samples have been created at room temperature without any additional heat conditioning or post treatment.

Remarkably, only minor oxidization occurs on the surface of the printed structures, which is attributed to the pneumatic actuation by nitrogen, as described above. These examples demonstrate that it is possible to influence the properties of the printed structures (morphology, porosity, wall thickness, roughness, etc.) by variation of the process parameters considerably.

\section{Conclusion \& Outlook}

The described improved StarJet metal droplet generator V2 was successfully tested experimentally in continuous and DoD operation mode. The diameter of the star shaped nozzle chips could be decreased by the development of a novel fabrication process. This new process also features an increased surface quality of the chips, leading to an improved stability of the droplet generation process. Further, the miniaturized nozzle chips in combination with the redesigned V2 actuator with two pneumatic connections allows for higher frequencies $(f \max =11 \mathrm{kHz}$ ) and generation of smaller droplets $\left(D_{\min }=60 \mu \mathrm{m}\right)$ than before. By adjustment of the actuation pressure, as well as the rinse pressure alone, the dispensing frequency can be adjusted in a wide range. Furthermore, microdroplets of ZAMAK have been printed for the first time at temperatures as high as $500{ }^{\circ} \mathrm{C}$, which are not feasible with piezo-driven droplet generators. 
The presented printing experiments demonstrate that the StarJet technology can be successfully applied for the 3D-prototyping of porous and non-porous metal structures. The generated structures show clearly that depending on droplet temperature, as well as other printing parameters, the porosity and wall thickness of the printed structures is controllable. These printing experiments are, of course, only a first step towards the defined prototyping of metal microstructures by direct printing of liquid metal. More work has to be dedicated to study the solidification and the resulting morphology of the metal surface as a function of materials and process parameters before more complex shapes can be generated. In future work, the StarJet method will be also applied at even higher temperatures to enable a wider choice of materials to be used for direct metal printing.

\section{Acknowledgments}

Funding by the German Federal Ministry of Education and Research (FKZ 02PO2872) is gratefully acknowledged.

\section{References}

1. Schuhmacher, D., Scheithauer H., Alavi, M., Niekrawietz,R., Hei, B., Zengerle, R., Koltay, P., Erzeugung von Mikrotropfen aus flüssigem Lötzinn mittels einer hochparallelen und kontaktlosen Drucktechnik. In Proceedings of MikroSystemTechnik—KONGRESS 2007, Dresden, Germany, October 2007; pp. 357-360.

2. Ho-Young, S.; Jae-Woong, N.; Kyung-Wook, P. Formation of Pb/63Sn solder bumps using a solder droplet jetting method. IEEE Trans. Electron. Packag. Manuf. 2005, 28, 274-281.

3. Ession, M.; Keicher, D.M.; Miller, W.D. Manufacturing electronic components in a direct-write process using precision spraying and laser irradiation. Patent EP1179288, 2000.

4. Cao, W.; Yoshinari, M. Freeform fabrication of aluminum parts by direct deposition of molten aluminum. J. Mater. Process. 2006, 173, 209-212.

5. Lee, T.-M.; Kang, T.G.; Yang, J.-S.; Jo, J.-D.; Kim, K.-Y.; Choi, B.-O.; Kim, D.-S. 3D metal microstrcture fabrication using a molten metal DoD inkjet system. In Proceedings of the 14th International Solid-State Sensors, Actuators and Microsystems Conference, Lyons, France, June 2007; pp. 1637-1640.

6. Orme, M.; Liu, Q.; Fischer, J. Mono-disperse aluminum droplet generation and deposition for net-form manufacturing of structural components. In Proceedings of the 8th International Conference on Liquid Atomization and Spray Systems, Pasadena, CA, USA, July 2000.

7. Irlinger, F.; Harnisch, J. Hochtemperatur-Tropfenerzeugung mittels eines elektromagnetischen Drop-on-Demand-Systems. In Proceedings of Mikrosystemtechnik Kongress 2005, Munich, Germany, October 2005.

8. Kessling, O.S.; Werner, K.; Irlinger, F.; Lüth, T.C. Indium solder printing for low temperature applications and modeling of a droplet generator. In Proceedings of the 2010 IEEE International Conference on Robotics and Biomimetics, Tianjin, China, December 2010.

9. Yamaguchi, K.; Sakai, K.; Yamanaka, T.; Hirayama, T. Generation of three-dimensional micro structure using metal jet. Precis. Eng. 2000, 24, 2-8. 
10. Priest, J.J.; Elizabeth Smith, C., Jr. Liquid metal jetting technology: Application issues for hybrid technology. Int. J. Microcircuits Elecron. Packag. 1994, 17, 219-227.

11. Schuhmacher, D.; Niekrawietz, R.; Scheithauer, H.; de Heij, B.; Alavi, M.; Zengerle, R.; Koltay, P. Production of solder microdroplets using a highly parallel and contact-free printing method. In Proceedings of the IEEE 20th International Conference on Micro Electro Mechanical Systems, Kobe, Japan, January 2007; 357-360

12. Kübler, M.; Lemmermeyer, B.; Wehl, W.; Wild, J. Ein akustisches Antriebssystem für einen Drop-on-Demand-Druckkopf. Horizonte 2006, 28, S3-S9.

13. Orme, M.; Courter, J.; Liu, Q.; Zhu, J.; Smith, R. Charged molten metal droplet deposition as a direct write technology. In Proceedings of the MRS 2000 Spring Meeting, San Francisco, CA, USA, April 2000.

14. Orme, M.; Smith, R.F. Enhanced aluminum properties by means of precise droplet deposition. $J$. Manuf. Sci. Eng. 2000, 122, doi:10.1115/1.1285914.

15. Tropmann, A.; Lass, N.; Paust, N.; Metz, T.; Ziegler, C.; Zengerle, R.; Koltay, P. Pneumatic dispensing of nano- to picoliter droplets of liquid metal with the StarJet method for rapid prototyping of metal microstructures. Microfluid. Nanofluid. 2011, 12, 75-84.

16. Lass, N.; Tropmann, A.; Metz, T.; Zengerle, R.; Koltay, P. 3D Rapid-Prototyping durch Drucken von flüssigem Metall unter Verwendung der StarJet. In Proceedings of Mikrosytemtechnik Congress 2012, Darmstadt, Germany, October 2011.

17. Riegger, L. Back-end Processing in Lab-on-a-Chip Fabrication. Ph.D. Thesis, University of Freiburg, Freiburg, Germany, 2010; Suedwestdeutscher Verlag für Hochschulschriften, ISBN: 3838120892.

18. Rangelow, I.W. Critical tasks in high aspect ratio silicon dry etching for microelectromechanical systems. J. Vac. Sci. Technol. A 2003, 21, doi:10.1116/1.1580488.

19. McNie, M.; Pickering, C.; Rickard, A.L.; Young, I.M.; Hopkins, J.; Ashraf, H.; McAuley, S.A.; Nicholls, G.; Barnett, R.; Roozeboom, F.; et al. Performance enhancement and evaluation of deep dry etching on a production cluster platform. Proc. SPIE Micromach. Microfabr. Process Technol. VIII 2003, 4979, doi:10.1117/12.478242.

20. Aziz, S.D.; Chandra, S. Impact, recoil and splashing of molten metal droplets. Int. J. Heat Mass Transf. 2000, 43, 2841-2857.

(C) 2013 by the authors; licensee MDPI, Basel, Switzerland. This article is an open access article distributed under the terms and conditions of the Creative Commons Attribution license (http://creativecommons.org/licenses/by/3.0/). 